\title{
Effects of Irrigation and Tree Spacing on Soil and Air Temperature Profiles of Olive Orchards
}

\author{
José A. Andrade ${ }^{1}$, Francisco L. Santos ${ }^{1}$, Manuela Correia ${ }^{1}$, Teresa A. do Paço ${ }^{2}$ \\ IInstituto de Ciências Agrárias e Ambientais Mediterrâneas (ICAAM), Universidade de Évora, Portugal \\ ${ }_{2}$ Biosystems Engineering - Water, Natural Resources and Climate, Instituto Superior de Agronomia, \\ Technical University of Lisboa, Portugal
}

Keywords: olive orchards, soil temperature, air temperature, shading, irrigation, damping depth

\begin{abstract}
Changes on the climate of the boundary layer occur when a vegetation cover above a bare soil is introduced, namely on temperatures and humidity profiles, above and under soil surface. Since air and soil temperatures affect crop growth and development and also soil moisture, they have been used as driving variables in numerous crop growth and development models as well as in those referred to soil mineralization, evaporation, transpiration, etc. The aim of this work was to evaluate (a) the soil thermal behavior in two olive orchards (Olea europaea sp. europaea), both grown on soils with little profile development (Regosol and Cambisol) and subject to drip irrigation but with different spacing between trees, and (b) the air thermal profile over olive rows. Experiments were performed from April to June 2012 in Southern Portugal. Soil and air temperatures were measured by thermocouples. The two orchards changed spatial distribution of soil surface temperature, soil temperature profiles and air temperature within the canopy, either on a daily or hourly basis. Olive tree spacing and irrigation affected both the soil thermal behavior and air thermal profiles. Tree spacing affected the horizontal gradients established along the interrows (intensity and rhythm). Irrigation reduced hourly and daily mean soil surface temperatures and daily thermal amplitudes of both profiles. Differences were also found on damping depths of the thermal wave estimated for the driest and the wettest profiles. Along the row, the effect of shading seems to overlap that of irrigation in a hourly basis.
\end{abstract}

